\title{
SPOROTRICHOSIS IN THE DIFFERENTIAL DIAGNOSIS OF ULCERATIVE LESION IN A PATIENT PRESENTING WITHMIXED CONNECTIVE TISSUE DISEASE: CASE REPORT
}

Thiago Henrique da Silva Rached ${ }^{1}$, Túlia Silva Freire ${ }^{1}$, Villane Matheus Fernandes Silva1, Raquel Anne Bacurau Monteiro ${ }^{1}$, Hugo Deleon de Lima ${ }^{1}$, Beatriz Afonso Ferreira Coelho Silton ${ }^{1}$, Maria Regina Macêdo Campos ${ }^{1}$, Lígia Helena de Melo Rosendo ${ }^{1}$, Laurindo Ferreira da Rocha Junior ${ }^{1}$

1.Instituto de Medicina Integral Professor Fernando Figueira, Recife (PE), Brazil.

*Corresponding author: hugodeleondelima@gmail.com

\section{BACKGROUND}

Mixed connective tissue disease (MCTD) is a connective tissue disease that incorporates selected clinical features of systemic lupus erythematosus, systemic sclerosis, and polymyositis characterized by the presence of high titers of anti-U1-ribonuclear protein (RNP) autoantibodies. Chronic ulcers in MCTD have been reported to be due to subcutaneous calcification, vasculitis, nonspecific inflammation, Antiphospholipid antibodies. Cutaneous sporotrichosis infections can be difficult to visually distinguish from other ulcerative or infiltrative lesions particularly in patients with connective tissue diseases. We present a case of a patient presenting with MCTD and ulcerative lesion caused by sporotrichosis.

\section{CASE REPORT}

A 35-year-old female patient was referred to our outpatient rheumatology clinic with a 9-month history of polyarthralgia, Raynaud phenomenon, acrosclerosis, weight loss (10 kg in 2 months), puffy fingers, dysphagia, right wrist arthritis, panniculitis of the right thigh and painful ulcerative lesion in the left forearm (with onset in the last 4 months). Laboratory tests demonstrated high erythrocyte sedimentation rate ( $76 \mathrm{~mm}$ in the first hour), high titers of ANA (1/1280), positive rheumatoid factor and high titers of anti-RNP antibodies. Anti-DNA, anti-SM, anticentromere, anti-Sc170, antiphospholipid and anti-SSA/SSB antibodies were negative. Esophageal transit scintigraphy showed prolonged esophageal clearance. The patient was diagnosed with MCTD according to Alarcón-Segovia criteria and underwent skin biopsy, in which there was a diffuse infiltration of neutrophils through the dermis suggesting pyoderma gangrenosum. Later she developed papules in the left upper limb with lymphocutaneous spread. She started therapy with prednisone $20 \mathrm{mg} /$ day and hydroxychloroquine $400 \mathrm{mg} /$ day with no improvement of the lesion. Then, she performed culture of aspirated material from the lesion that identified Sporothrix schenckii. Itraconazole ( $200 \mathrm{mg} /$ day) was promptly started. Treatment continued for 7 months leading to complete wound regression and healing of the left arm. After 30 days of itraconazole therapy, she started azathioprine $100 \mathrm{mg} /$ day and maintained hydroxychloroquine with improvement of the MCTD symptoms.

\section{CONCLUSION}

Ulcerative skin manifestations of MCTD might be present at the onset of symptoms. Sporotrichosis might mimic ulcerative lesions associated with connective tissue diseases specially pyoderma gangrenosum. Differential etiologies of ulcers in systemic autoimmune diseases are a diagnostic challenge. 